\title{
COMPORTAMENTO RECENTE DO SETOR FLORESTAL MADEIREIRO NO ESTADO DO PARÁ, BRASIL ${ }^{1}$
}

\author{
Ricardo Bruno Nascimento dos Santos² e Antônio Cordeiro de Santana ${ }^{3}$
}

\begin{abstract}
RESUMO - Os objetivos deste trabalho foram analisar o comportamento das exportações de madeira e identificar os municípios especializados nas atividades florestal e de madeira e mobiliário, no período de 1998 a 2004. A metodologia utilizada foi a taxa geométrica de crescimento (TGC), bem como o índice de concentração normalizado (ICN). Os resultados indicaram que as exportações cresceram a uma TGC acima de $14 \%$ ao ano. Foram identificados 25 municípios especializados em madeira e mobiliário e cinco na atividade florestal.
\end{abstract}

Palavras-chave: Economia florestal, certificação de madeira e manejo florestal.

\section{RECENT BEHAVIOR OF THE SECTION FOREST LUMBERMAN IN THE STATE OF PARÁ, BRAZIL}

\begin{abstract}
The objective of this work was to analyze the behavior of wood exports and to identify the municipalities specialized on forestry, wood and furniture activities, in the period from 1998 to 2004. The methodology applied was the rate of geometric growth $(R G G)$ and the normalized index of concentration (NIC). The results showed that the exports grew at a rate of over 14\% a year. Furthermore, twenty-five municipalities were identified as being specialized in wood and furniture; and five in forestry activities.
\end{abstract}

Keywords: Forest economy, forest certification and State of Pará.

\section{INTRODUÇÃO}

No Brasil, 66\% das áreas rurais estão cobertas por florestas naturais, $0,5 \%$ por florestas plantadas e o restante $(33,5 \%)$ por outros usos, como agricultura, pecuária e áreas urbanas. Das áreas com floresta natural, $64 \%$ (412 milhões de hectares) são de florestas densas, $26 \%$ com outras formas de vegetação natural e os $10 \%$ restantes com floresta aberta (ABIMCI, 2003). Com relação à localização, $61 \%$ das florestas naturais encontram-se distribuídas em três estados da Amazônia Legal: Amazonas (26,2\%), Pará $(23,7 \%)$ e Mato Grosso (11,2\%) (ABIMCI, 2003). Desses três estados, o Pará se destaca pela extração de madeira em tora, beneficiamento e liderança na exportação de diversos produtos madeireiros.

A cadeia de produção de produtos madeireiros da floresta nativa gerou 4,5\% do PIB em 2002, ou seja, cerca de US\$ 20 bilhões (NOCE et al., 2005). A indústria madeireira contribuiu com $2 \%$ desse valor e, segundo dados da Abimici (2003), com US\$4,6 bilhões em impostos, correspondendo a $2 \%$ da arrecadação total. Além disso, ocupou 6,5 milhões de pessoas em toda a cadeia, cerca de $9 \%$ da PEA.

Nesse contexto, o Estado do Pará, entre 1998 e 2002, extraiu e beneficiou $11.020 .472 \mathrm{~m}^{3}$ de madeira em tora, cerca de $30 \%$ da produção nacional. Essa atividade,

\footnotetext{
${ }^{1}$ Recebido em 23.01.2007 e aceito para publicação em 24.04.2009.

${ }^{2}$ Programa de Pós-Graduaçãoem Ciências Florestais da UniversidadeFederal Rural daAmazônia(UFRA). E-mail: <ricardo-bruno@gmail.com>.

${ }^{3}$ UFRA, Av. Tancredo Neves, 2501, CEP 66.077-530 Belém, Pará. E-mail: <antonio.campos@ @q.cnpq.br>.
} 
por sua vez, é desenvolvida, predominantemente, por micro e pequenas empresas (SANTANA, 2002). Em 2005, o Pará foi o terceiro no ranking das exportações, concentrando $75 \%$ da madeira extraída de floresta nativa do país. Da madeira extraída na Amazônia Legal, 64\% destina-se ao mercado doméstico e $36 \%$ à exportação. Tanto a Amazônia Legal quanto São Paulo consomem $11 \%$, o Sul e o Sudeste $27 \%$ e o Nordeste $7 \%$ de madeira extraída da região amazônica.

Em razão do grande estoque de madeira, as serrarias em articulação com as atividades agrícolas e pecuárias produziram grande impacto sobre as florestas densas do Estado do Pará. Segundo estudos de Homma (1993), Santana (2002, 2003), Fearnside (2003) e Alencar et al. (2004), o desmatamento é incentivado por dinâmicas ligadas à demanda por madeira do resto do Brasil, do mercado internacional e das atividades agrícola e pecuária na Amazônia.

Com relação ao impacto sobre o desmatamento, os dados do Instituto Nacional de Pesquisas Espaciais ${ }^{1}$ (Inpe) mostram uma área desmatada na Amazônia Legal de $700 \mathrm{mil} \mathrm{km²}$, em 2005. A área desmatada compõe a faixa denominada arco do desmatamento, cujos limites abrangem o sudeste do Estado do Maranhão, norte de Tocantins, sul do Pará, norte do Mato Grosso, Rondônia, sul do Amazonas e sudeste do Acre.

Estudos de Santana $(2001,2002)$ mostraram que a extração e beneficiamento da madeira no Estado do Pará são feitos por um conjunto dominante de micro e pequenas empresas especializadas na produção de madeira serrada, móveis e artefatos de madeira $(92,4 \%$ do total), bem como por um conjunto menor de médias e grandes empresas que produzem laminado, compensado e aglomerado de madeira (7,6\% do total), formando em alguns locais uma concentração industrial com produtos diversificados a partir da madeira em tora. Essas aglomerações de empresas, associadas a um conjunto de outras unidades produtivas com algum vínculo horizontal com as empresas madeireiras, configuram o que se passou a chamar no Brasil de Arranjos Produtivos Locais (APL). O termo APL foi cunhado pela RedeSist (LASTRES et al., 1998; LASTRES; CASSIOLATO, 2005) e é formado "por conjuntos de agentes econômicos, políticos e sociais, localizados em um mesmo território e vinculados a uma atividade ou setor econômico, que apresentam vínculos de articulação, interação, cooperação e aprendizagem, mesmo que incipientes".

A capacidade demonstrada por aglomerações empresariais desse tipo para gerar emprego e renda e alavancar processos de desenvolvimento sustentável a partir dos locais despertou o interesse de órgãos públicos em adotar tais estruturas como unidade de planejamento do desenvolvimento local sustentável (MYTELKA; FARINELLI, 2000; SANTANA, 2004; SANTANA; SANTANA, 2004). Em função da importância do setor florestal para o desenvolvimento sustentável da economia paraense, adotou-se o conceito de APL pelo potencial em atender às demandas dos mercados de madeira das demais unidades da federação e do mercado internacional, cujas exigências aumentaram por madeiras oriundas de planos de manejo sustentáveis, conforme estudos de Kiker et al. (1997) e Hasnmann et al. (2003).

O objetivo deste trabalho foi analisar o comportamento das exportações de produtos madeireiros e determinar a localização espacial dos APL do setor florestal e de madeira e mobiliário no Estado do Pará, no período de 1988 a 2004.

\section{MATERIAL E MÉTODOS}

A área de estudo foi o Estado do Pará, eleita em função da importância do setor florestal na geração de emprego e renda e nas exportações. A base de dados utilizada na análise comportamental das exportações e importações foi do sistema Alice Web do Ministério do Desenvolvimento, da Indústria e Comércio (MDIC).

As informações sobre a certificação florestal foram obtidas dos relatórios do Forest Stewarship Council (FSC) e das publicações disponibilizadas no site do Instituto Brasileiro do Meio Ambiente e dos Recursos Naturais Renováveis (Ibama).

Para identificar os municípios especializados ou que apresentam concentrações de empresas na atividade de exploração florestal e de madeira e mobiliário, utilizouse a base de dados sobre o número de empregos formais da Relação Anual de Informações Sociais (Rais) do

\footnotetext{
${ }^{1}$ www.inpe.gov.br
}

R. Árvore, Viçosa-MG, v.33, n.3, p.533-543, 2009 
Ministério do Trabalho e Emprego (MTE-Caged). O emprego formal é uma variável que representa o mercado de trabalho local e funciona como fonte de atração de pessoas e empresas para o local, além de representar uma das forças que explicam o surgimento das aglomerações empresariais.

Para analisar a evolução das exportações e importações de produtos madeireiros, utilizou-se o cálculo da Taxa Geométrica de Crescimento (TGC), de acordo com Santana e Silva (1998).

Para o cálculo da TGC, foi utilizada a seguinte expressão:

$$
\log Y_{t}=a+b T_{t}+\varepsilon_{t}
$$

em que $Y_{t}$ representa o logaritmo do valor da variável importação e exportação em análise; $a$ é o valor da constante de regressão; $b$ é o coeficiente de regressão; $T_{t}$ é a tendência cronológica; e $\varepsilon_{t}$ é o erro aleatório. Para valores de $b$ diferentes de zero, calculou-se a TGC da seguinte maneira:

$$
\begin{aligned}
& \text { Ant } \log b=1+T G C \\
& T G C=(A N T \log b-1) \times 100
\end{aligned}
$$

Para a conversão dos valores das exportações e das importações, utilizou-se a taxa de câmbio média do dólar livre para a venda, obtido no site do Banco Central do Brasil. Para deflacionar os valores em reais, utilizou-se o índice IGP-DI da Fundação Getúlio Vargas, tendo como base o mês de dezembro do ano de 2005.

Para identificar os municípios especializados nos APL de exploração florestal e de madeira e mobiliário, utilizou-se a metodologia referenciada por Suzigan et al. (2001) e Crocco et al. (2003), aprimorada por Santana (2004). Diferentemente dos demais autores, Santana (2004) uniu classes de atividades relacionadas a dado elo da cadeia produtiva, em que ocorrem algumas operações como a compra de insumos, venda de produtos e compartilhamento de transporte e serviços. Os estudos empregam todos ou alguma combinação dos indicadores de especialização apresentados, em seguida, para determinar a localização geográfica de APL.

O primeiro indicador é o Quociente Locacional (QL), que serve para determinar se um município em particular possui especialização em dada atividade ou setor específico, sendo calculado com base na razão entre duas estruturas econômicas. No numerador, tem- se a economia em estudo e no denominador, a economia de referência:

$$
\mathrm{QL}=\left(\frac{\mathrm{E}_{\mathrm{j}}^{\mathrm{i}}}{\mathrm{E}_{\mathrm{j}}} \frac{\mathrm{E}_{\mathrm{p}}^{\mathrm{i}} / \mathrm{E}_{\mathrm{P}}}{\mathrm{E}_{\mathrm{p}}}\right)
$$

em que $E_{j}^{i}$ é o emprego da atividade ou setor i no município em estudo do Estado do Pará; $\mathrm{E}_{\mathrm{j}}$ é o emprego referente a todas as atividades que constam nos municípios paraenses; $\mathrm{E}_{\mathrm{p}}^{\mathrm{i}}$ é o emprego da atividade ou setor i no Estado do Pará; e $\mathrm{E}_{\mathrm{P}}$ é o emprego de todas as atividades ou setores do Pará. Para esse indicador, um QL > 1 indica que o município é especializado no APL em pauta.

O segundo indicador é o Índice de HirschmanHerfindahl (IHH) que permite comparar o peso da atividade ou setor i do município do Pará no setor i do Estado em relação ao peso da estrutura produtiva no município j na estrutura estadual como um todo. Esse índice pode ser encontrado por meio da seguinte fórmula:

$$
\mathrm{IHH}=\left(\frac{\mathrm{E}_{\mathrm{j}}^{\mathrm{i}}}{\mathrm{E}_{\mathrm{p}}^{\mathrm{i}}}\right)-\left(\frac{\mathrm{E}_{\mathrm{j}}}{\mathrm{E}_{\mathrm{p}}}\right)
$$

Um valor positivo indica que a atividade ou setor i do município do Estado do Pará tem ali maior concentração de empresas ou atividades e, portanto, maior poder de atração econômica, dada a especialização de tal atividade no setor.

O terceiro indicador é a Participação Relativa (PR). Foi utilizado para captar a importância da atividade ou setor i no município j diante do total de emprego na referida atividade no Estado do Pará, isto é, a participação relativa da atividade ou setor no emprego total da respectiva atividade ou setor no Pará. A fórmula é dada por:

$$
P R=\left(\frac{E_{j}^{i}}{E_{P}^{i}}\right)
$$

Esse indicador varia entre zero e 1. Quanto mais próximo de 1, maior a importância da atividade ou setor i do município j no Pará.

Por fim, o Índice de Concentração Normalizado (ICn) foi construído por meio de uma combinação linear dos outros três indicadores, conforme Crocco et al. (2003) e Santana (2004). O ICn é dado pela equação:

R. Árvore, Viçosa-MG, v.33, n.3, p.533-543, 2009 


$$
\mathrm{ICn}_{\mathrm{ij}}=\theta_{1} Q L_{i j}+\theta_{2} I H H_{i j}+\theta_{3} P R_{i j}
$$

em que os pesos $\theta$ representam a contribuição de cada um dos indicadores na construção do ICn. O cálculo dos pesos $\theta$ foi realizado por meio da técnica multivariada de Análise de Componentes Principais (ACP), conforme descrito em Dillon e Goldstein (1984) e Santos (2006). Quanto maior o valor do ICn, maior a concentração da atividade no município, ou seja, quanto maior esse indicador em relação ao valor médio, maior a possibilidade de o município ter concentração de atividades ou empresas com potencial de se transformar em APL.

\section{RESULTADOS E DISCUSSÃO}

\subsection{Comportamento das exportações e importação de produtos madeireiros}

Com relação às exportações brasileiras do setor de exploração florestal, os dados revelaram que, desde 1997, alguns produtos do setor de madeira e mobiliário tiveram queda significativa nos valores de exportação, com destaque para as atividades de menor valor agregado como "madeira em bruto", "arcos de madeiras, estacas fendidas" e "lã de madeira e farinha de madeira", que apresentaram taxas geométricas de crescimento, respectivamente, de $(-27,60 \%)$, $(-29,25 \%)$ e $(-28,95 \%)$, conforme Tabela 1 .

Dessas atividades, a taxa de crescimento para "madeira em bruto" foi significativa no nível de $1 \%$ de probabilidade; para "arcos de madeiras e estacas fendidas", não foi significativa; e para "lã de madeira e farinha de madeira" foi significativa a $10 \%$. Esses produtos apresentaram baixa participação no valor total de exportação.

Nas exportações dos demais produtos, constatouse que o setor de madeira e mobiliário apresenta, no geral, taxas geométricas de crescimento (TGC) estatisticamente significativas e superiores a $20 \%$, contribuindo para gerar um saldo positivo da balança comercial. Observa-se que as TGC das importações foram inferiores às obtidas nas exportações brasileiras de produtos madeireiros, sinalizando manter sustentável o saldo da balança comercial em função da agregação de valor aos produtos certificados da exploração florestal e de madeira e mobiliário.

No Estado do Pará, apenas um dos produtos exportados (folhas de madeira) não apresentou tendência significativa de crescimento. Isso demonstra maior competitividade dos produtos, em função da especificidade de ser originário de floresta nativa, em relação à pauta de exportação brasileira, contribuindo para manter e, ou aumentar o superávit da balança comercial nacional. No ano de 1997, o Estado do Pará tinha uma participação de $30,39 \%$ no saldo da balança comercial, decrescendo ao longo dos anos e chegando, em 2005, a 19,48\% (Tabela 2). Isso ocorreu porque o valor agregado dos produtos exportados pelo Estado do Pará evoluiu mais lentamente que no resto do Brasil.

Os produtos paraenses que mais se destacaram no setor de madeira e mobiliário foram madeira serrada, com uma TGC de $8,48 \%$, superior ao crescimento das exportações brasileiras e madeira compensada, com crescimento de $8,26 \%$ que, juntos, responderam, na média dos anos, por $72,58 \%$ do total exportado. Em termos de agregação tecnológica, o destaque se refletiu no avanço das exportações de painéis de madeira $(83,91 \%)$, madeira perfilada $(58,07 \%)$ e obras de madeira beneficiada $(13,23 \%)$.

Esse desempenho competitivo se deve, por um lado, ao fato de o Brasil possuir grande estoque de madeira nativa tropical e estar entre os oito maiores exportadores de madeira serrada no mundo (NOCE et al., 2005) e, por outro lado, às exigências do mercado consumidor nacional e internacional, segundo Oliveira et al. (2005), agregando valor aos produtos e aplicando metodologias de exploração sustentável da floresta.

Naturalmente, essa ampliação das exportações de madeira de floresta nativa do Estado do Pará tem causado grande impacto sobre os recursos naturais ao longo do tempo, mediante o desmatamento de grandes áreas de florestas densas. Para fazer frente a esse processo de extrativismo por aniquilamento, a exploração madeireira só é permitida em áreas sob manejo sustentável e, ou, sob autorização de desmatamento.

\subsection{Manejo e da Certificação Florestal no Estado do Pará}

Com a pressão global sobre o meio ambiente, criouse na Amazônia um palco de discussão sobre a preservação e, ou, exploração sustentável da floresta. Um dos pontos polêmicos e de grande interesse diz respeito à extração desordenada e, ou, ilegal de madeira em tora na Amazônia Legal.

Atualmente, a madeira em tora extraída em florestas naturais da Amazônia pode ser legalmente adquirida por dois caminhos: primeiro, pelo Plano de Manejo Florestal Sustentável (PMFS), que é fiscalizado pelo Ibama, juntamente com a Secretaria de Meio Ambiente (Sema-PA); segundo, por meio de Autorizações de Desmatamento, que restringem o desmatamento a $20 \%$ das áreas registradas como propriedades rurais, com presença de florestas. 
Tabela 1 - Exportação-importação de produtos do setor madeireiro no Brasil de 1997 a 2005 em (R $\$ 1.000)$, a preços de dezembro de 2005

Table 1 - Export-Import product of products of the section Lumberman in Brazil from 1997 to 2005 at prices of December of 2005 in (R\$ 1.000$)$

\begin{tabular}{|c|c|c|c|c|c|c|c|c|c|c|}
\hline \multirow{3}{*}{ Produtos } & \multicolumn{9}{|c|}{ Exportação Brasil } & \multirow{3}{*}{$\mathrm{TGC}(\%)$} \\
\hline & 1997 & 1998 & 1999 & 2000 & 2001 & 2002 & 2003 & 2004 & 2005 & \\
\hline & $\mathrm{R} \$$ & $\mathrm{R} \$$ & $\mathrm{R} \$$ & $\mathrm{R} \$$ & $\mathrm{R} \$$ & $\mathrm{R} \$$ & $\mathrm{R} \$$ & $\mathrm{R} \$$ & $\mathrm{R} \$$ & \\
\hline Madeiras em estilhas ou partículas & 49.262 & 77.727 & 106.103 & 144.621 & 159.992 & 188.888 & 207.444 & 258.952 & 245.865 & $21,43^{*}$ \\
\hline Carvão vegetal & 1.510 & 3.419 & 5.762 & 3.897 & 7.045 & 7.257 & 8.678 & 17.079 & 9.437 & $25,43^{*}$ \\
\hline Madeira em bruto & 68.472 & 90.924 & 64.587 & 77.650 & 58.388 & 84.344 & 13.323 & 15.582 & 4.364 & $-27,60 *$ \\
\hline Arcos de madeira, estacas fendidas etc. & 51.982 & 76.434 & 50.915 & 406 & 367 & 84 & 2.422 & 11.928 & 7.913 & $-29,25^{\text {ni }}$ \\
\hline Lã de madeira e farinha de madeira* & 28 & 23 & 3 & 35 & 1 & 19 & 2 & 3 & 0 & $-28,95^{* * * *}$ \\
\hline Dormentes de madeira para vias férreas & 0 & 0 & 0 & 209 & 958 & 723 & 3.175 & 559 & 2.276 & $764,80 *$ \\
\hline Madeira serrada & 784.041 & 827.703 & 1.441 .341 & 1.431 .467 & 1.750 .805 & 2.100 .937 & 2.263 .207 & 2.590 .916 & 2.147 .373 & $15,68^{*}$ \\
\hline Folhas de madeira & 144.628 & 111.368 & 123.226 & 112.753 & 105.725 & 147.959 & 144.955 & 169.935 & 166.670 & $4,14 * * *$ \\
\hline Madeira perfilada & 94.941 & 93.620 & 206.348 & 278.722 & 291.928 & 386.719 & 530.293 & 873.713 & 1.038 .160 & $36,08^{*}$ \\
\hline Painéis de madeira & 39.258 & 22.692 & 22.682 & 28.810 & 42.001 & 35.803 & 64.010 & 160.382 & 119.879 & $23,42^{*}$ \\
\hline Painéis de fibra de madeira & 150.202 & 136.927 & 199.463 & 164.091 & 192.742 & 316.760 & 359.272 & 338.238 & 308.352 & $13,17^{*}$ \\
\hline Madeira compensada & 503.759 & 402.222 & 999.911 & 1.029 .563 & 1.184 .402 & 1.598 .569 & 2.061 .013 & 2.763 .283 & 1.912 .629 & $24,20 *$ \\
\hline Outras obras de madeira beneficiadas & 394.804 & 414.515 & 777.618 & 779.369 & 1.097.373 & 1.558 .278 & 1.605 .287 & 2.203 .838 & 1.412 .705 & $22,66^{*}$ \\
\hline $\begin{array}{l}\text { Serragem, desperdícios e resíduos } \\
\text { de madeira }\end{array}$ & 1 & 21 & 0 & 3 & 48 & 163 & 6.473 & 7.893 & 3.415 & $247,38^{*}$ \\
\hline \multirow[t]{2}{*}{ Total Exportação } & 2.282 .887 & 2.257 .596 & 3.997 .960 & 4.051 .597 & 4.891 .775 & 6.426 .504 & 7.269 .552 & 9.412 .299 & 7.379 .035 & $19,39 *$ \\
\hline & \multicolumn{9}{|c|}{ ImportaçãoBrasil } & \\
\hline Madeiras em estilhas ou partículas & 75 & 429 & 551 & 394 & 465 & 597 & 171 & 105 & 252 & $-2,16^{\mathrm{ns}}$ \\
\hline Carvão vegetal & 405 & 697 & 507 & 612 & 920 & 1.037 & 1.421 & 2.937 & 3.812 & $30,29 *$ \\
\hline Madeira em bruto & 1.905 & 4.658 & 3.062 & 4.616 & 9.915 & 3.546 & 2.666 & 2.700 & 3.468 & $0,37^{\text {ns }}$ \\
\hline Arcos de madeira, estacas fendidas etc. & 4.029 & 1.823 & 1.819 & 1.541 & 1.593 & 1.047 & 300 & 422 & 62 & $-34,14^{*}$ \\
\hline Lã de madeira e farinha de madeira & 0 & 11 & 0 & 4 & 36 & 8 & 25 & 132 & 51 & $231,62 * *$ \\
\hline Dormentes de madeira para vias férreas & 814 & 1 & 0 & 552 & 505 & 83 & 503 & 442 & 564 & $98,91^{\mathrm{ns}}$ \\
\hline Madeiraserrada & 27.078 & 25.490 & 15.220 & 14.931 & 23.428 & 28.915 & 30.301 & 34.389 & 26.127 & $4,77^{\text {ns }}$ \\
\hline Folhas de madeira & 21.613 & 20.969 & 27.015 & 31.831 & 29.962 & 46.702 & 29.520 & 28.345 & 19.527 & $1,78^{\mathrm{n}}$ \\
\hline Madeira perfilada & 4.316 & 7.575 & 4.228 & 3.795 & 1.416 & 1.878 & 1.214 & 981 & 5.823 & $-12,68^{\text {ni }}$ \\
\hline Painéis de madeira & 51.596 & 34.486 & 23.739 & 47.467 & 34.592 & 30.621 & 35.341 & 46.548 & 36.331 & $-0,24^{\text {na }}$ \\
\hline Painéis de fibra de madeira & 71.469 & 68.755 & 55.262 & 65.905 & 44.558 & 25.224 & 73.910 & 97.372 & 72.212 & $1,18^{\mathrm{n}}$ \\
\hline Madeiracompensada & 2.664 & 2.350 & 2.866 & 2.159 & 3.363 & 3.780 & 8.352 & 5.394 & 5.566 & $14,53^{*}$ \\
\hline Outras obras de madeira beneficiadas & 26.874 & 44.116 & 29.965 & 18.455 & 27.577 & 19.625 & 19.562 & 19.279 & 19.081 & $-7,45^{\text {** }}$ \\
\hline $\begin{array}{l}\text { Serragem, desperdícios e resíduos } \\
\text { de madeira }\end{array}$ & 65 & 416 & 452 & 388 & 465 & 569 & 143 & 80 & 240 & $-2,67^{\text {ns }}$ \\
\hline Total importação & 212.902 & 211.776 & 164.689 & 192.649 & 178.797 & 163.633 & 203.429 & 239.126 & 193.117 & $0,39 * *$ \\
\hline Saldo na balança comercial & 2.069 .985 & 2.045 .820 & 3.833 .271 & 3.858 .948 & 4.712 .979 & 6.262 .871 & 7.066 .124 & 9.173 .173 & 7.185 .918 & $20,50^{*}$ \\
\hline
\end{tabular}

Fonte: Montada pelos autores a partir dos dados do MDIC, Secex

Significativo a $1 \% ; * *$ significativo a $5 \% * * * *$ significativo a $10 \%$; e ns, não significativo.

* Corresponde a desperdícios ou resíduos de madeira, mesmo aglomerados em bolas, briquetes, pellets ou em formas semelhantes. 
Tabela 2 - Exportação-importação de produtos madeireiros no Estado do Pará de 1997 a 2005 em (R\$ 1.000), a preços de dezembro de 2005

Table 2 - Export-Import product Lumberman in Pará-Brazil from 1997 to 2005 at prices of December 2005 in (R\$ 1.000$)$

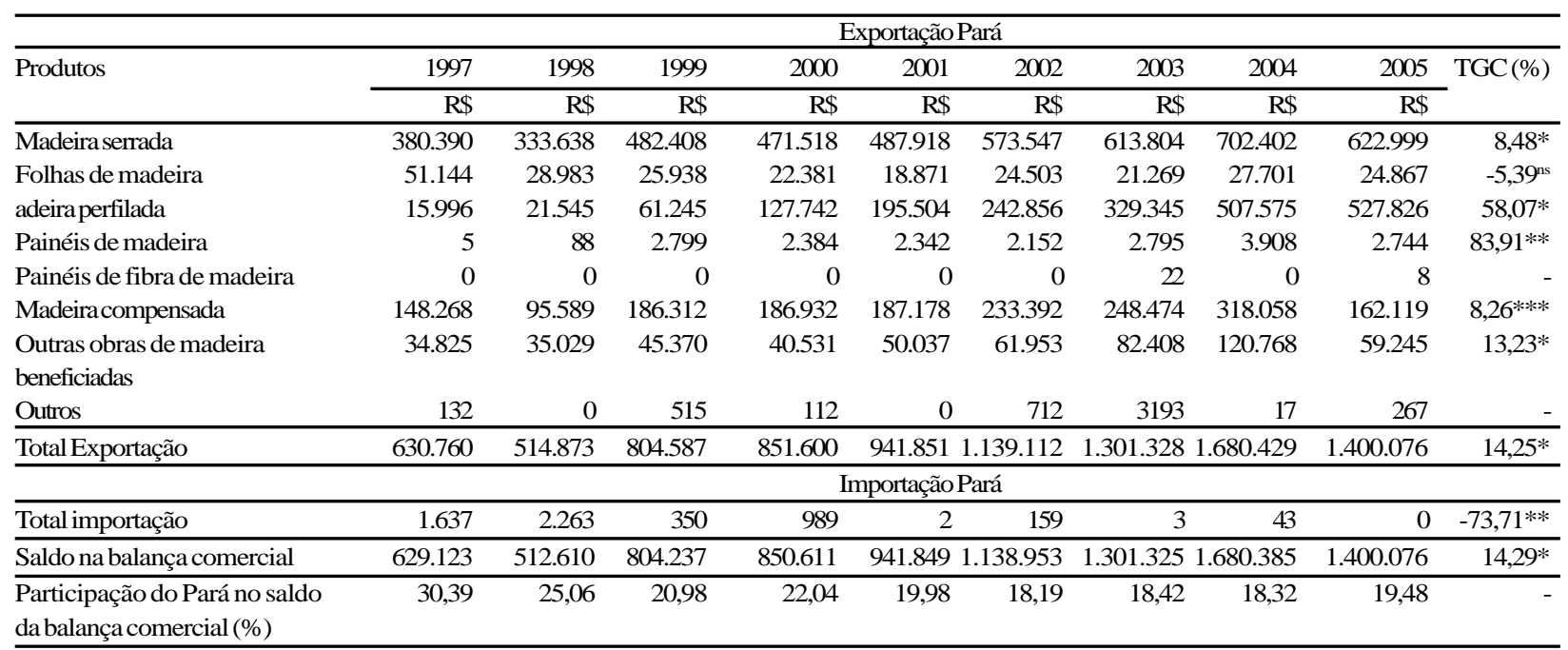

Fonte: Montada pelo autor a partir dos dados do MDIC, Secex.

* Significativo a $1 \%$; ** Significativo a $5 \%$; *** Significativo a $10 \%$; e ns, não significativo.

Em 2000, o Ibama tinha 389 planos de manejos aprovados que ocupavam 185 mil hectares. Em 2001, foram aprovados 549, cobrindo uma área de $340 \mathrm{mil}$ hectares, e 9,3 milhões de metros cúbicos tiveram autorização para serem explorados por meio de plano de manejo. Em 2003, o volume de madeira em tora a ser explorado ficou em cerca de 8,3 milhões de metros cúbicos e, em 2004, subiu para 14\% (Tabela 3).

Desses planos, a maior parte, tanto em área quanto em volume de madeira explorado, está no Estado do Pará. Em 2004, o Estado era responsável por quase $60 \%$ da área e pouco mais de $60 \%$ de volume explorado pelo PMFS.

Em 2000, o Ibama autorizou a exploração de 5,3 milhões de $\mathrm{m}^{3}$ de madeira em tora por meio de Autorizações de Desmatamento. Em 2003, esse volume caiu para 2,7 milhões de metros cúbicos e voltou a aumentar em 2004 para 4,6 milhões (Tabela 4).

Tabela 3 - Área e volume explorado nos PMFS aprovados pelo Ibama, 2000-2004

Table 3 - Area and volume explored in approved Plan of Maintainable Forest Handling by IBAMA, 2000-2004

\begin{tabular}{|c|c|c|c|c|c|c|c|c|}
\hline \multirow[t]{2}{*}{ Estado } & \multicolumn{2}{|c|}{2000} & \multicolumn{2}{|c|}{2001} & \multicolumn{2}{|c|}{2003} & \multicolumn{2}{|c|}{2004} \\
\hline & $\begin{array}{c}\text { Área } \\
\text { dos Planos } \\
\text { (1.000 há) }\end{array}$ & $\begin{array}{c}\text { Volume } \\
\text { Autorizado } \\
\left(1.000 \mathrm{~m}^{3}\right) \\
\end{array}$ & $\begin{array}{c}\text { Área } \\
\text { dos Planos } \\
\text { (1.000 há) }\end{array}$ & $\begin{array}{c}\text { Volume } \\
\text { Autorizado } \\
\left(1.000 \mathrm{~m}^{3}\right) \\
\end{array}$ & $\begin{array}{c}\text { Área } \\
\text { dos Planos } \\
\text { (1.000 há) }\end{array}$ & $\begin{array}{c}\text { Volume } \\
\text { Autorizado } \\
\left(1.000 \mathrm{~m}^{3}\right) \\
\end{array}$ & $\begin{array}{c}\text { Área } \\
\text { dos Planos } \\
\text { (1.000 há) }\end{array}$ & $\begin{array}{c}\text { Volume } \\
\text { Autorizado } \\
\left(1.000 \mathrm{~m}^{3}\right) \\
\end{array}$ \\
\hline Acre & 2,8 & 36,4 & 7,1 & 126,4 & 5,9 & 87,9 & 14,4 & 217,7 \\
\hline Amapá & 3,1 & 177 & 7,1 & 270 & 5,1 & 155,5 & 9 & 215,3 \\
\hline Amazonas & 17,4 & 417,8 & 22 & 662,6 & 24,4 & 635,6 & 20 & 459,2 \\
\hline Maranhão & 7,4 & 248,5 & 23,5 & 130,5 & 6 & 170,6 & 7,7 & 162,6 \\
\hline Mato Grosso & 86,3 & 2087,1 & 98,6 & 2180,4 & 70,5 & 16,7 & 59,6 & 1705,2 \\
\hline Pará & 41,6 & 533,3 & 132,7 & 4665,4 & 190,5 & 1670,6 & 201,9 & 5623,1 \\
\hline Rondônia & 25,6 & 632,4 & 49,4 & 1337,9 & 13,6 & 5043,8 & 29,3 & 961,9 \\
\hline Roraima & 0 & 0 & 0 & 0 & 0 & 453 & 0,3 & 8,1 \\
\hline Tocantins & 0,7 & 2 & 0 & 0 & 0 & 0 & 0 & 0 \\
\hline Total & 184,9 & 4134,5 & 340,4 & 9373,2 & 316 & 8233,7 & 342,2 & 9353,1 \\
\hline
\end{tabular}

Fonte: IBAMA, 2005.

R. Árvore, Viçosa-MG, v.33, n.3, p.533-543, 2009 
Tabela 4 - Volume de madeira oriundo de autorizações de desmatamento, 2000-2004

Table 4 - Volume of wood originating from of authorizations of deforestation, 2000-2004

\begin{tabular}{lcccc}
\hline Estado & \multicolumn{4}{c}{ Volume Autorizado em $1.000 \mathrm{~m}^{3}$} \\
\cline { 2 - 5 } & 2000 & 2001 & 2003 & 2004 \\
\hline Acre & 107,7 & 104,6 & 11,6 & 0 \\
Amapá & 29,4 & 109,9 & 35,1 & 193,3 \\
Amazonas & 193 & 92,7 & 28,8 & 113,1 \\
Maranhão & 2739,4 & 752,6 & 2172,4 & 3540,4 \\
Mato Grosso & 542 & 3703,7 & 164,7 & 21,9 \\
Pará & 534,1 & 121,6 & 42,1 & 97,7 \\
Rondônia & 428,2 & 227,7 & 5,8 & 144,1 \\
Roraima & 38,6 & 35,5 & 32 & 47 \\
Tocantins & 670,8 & 417,9 & 280 & 516,9 \\
\hline Total & 5283,2 & 5566,2 & 2772,5 & 4674,4 \\
\hline Fonte: IBA MA & 2005. & & &
\end{tabular}

Fonte: IBAMA, 2005.

Outro importante processo é a Certificação Florestal cuja atuação se dá pelos órgãos credenciadores no Brasil: o FSC - Forest Stewarship Council e o Cerflor - Certificado Florestal, lançado em fevereiro de 2003 pelo Inmetro (Tabela 5).

A certificação florestal, segundo a FSC (2006), é um mecanismo independente de autoria com o objetivo de avaliar a qualidade do manejo florestal e da silvicultura em todas as áreas florestais do mundo (nativas e plantadas). O FSC opera de acordo com princípios e critérios de manejo florestal, elaborados a partir de considerações sociais (respeito às leis trabalhistas e promoção do bem-estar dos trabalhadores e das comunidades vizinhas), econômicas (rentabilidade do empreendimento) e ambientais (redução de impactos e conservação da fauna, biodiversidade etc.). Atualmente, o Brasil possui três milhões de hectares certificados pelo FSC, o que corresponde a $16 \%$ da área certificada da América do Sul e 6\% no mundo. Dessa soma, 1,7 milhão de hectares estava na Amazônia Legal, num total de 22 empreendimentos certificados.

O Cerflor, por sua vez, começou a atuar em 2005, e até o momento certificou apenas duas empresas, uma do Espírito Santo e outra do Paraná, portanto está fora da Amazônia.

A certificação florestal no Estado do Pará teve início em 2000, mas foi em 2004 que a área total certificada aumentou significativamente, conforme pode ser visto na Figura 1. No Pará, são sete as empresas certificadas pelo FSC: Cikel (248.899 ha), Jari Celulose (427.736 ha), Emapa (12.000 ha), IBL - Izabel Madeiras do Brasil (20.000 ha), Orsa Florestal LTDA. (545.335 ha), Juruá Florestal (25.000 ha) e a Precious Wood Belém (76.390 ha). A soma total de área certificada é de 1,367 milhão de hectares, ou seja, só no Estado do Pará estão concentradas cerca de $79 \%$ das florestas certificadas na Amazônia Legal.

Essas empresas estão localizadas em Belém, Novo Repartimento, Tailândia, Almerim, Portel, Paragominas, Afuá e Breu Branco. No Município de Almerim, onde se localizam a Jari Celulose e a Precious Wood Amazon, observou-se a maior área certificada em hectares, ou seja, boa parte dos municípios está no corredor de concentração das atividade florestal e de madeira e mobiliário.

Outro ponto importante é o manejo florestal comunitário (Tabela 5), regulamentado pelo Ibama por meio das Instruções Normativas no 4 e 5 , que estabeleceram regras específicas para os Planos de Manejo Florestal de pequena escala. Segundo Lentini (2005), somente no Pará existiam 23 iniciativas com 166 famílias beneficiadas, em uma área de 47.547 hectares.

Tabela 5 - Áreas certificadas pelo FSC na Amazônia Legal por tipo de empreendimento, 2005 Table 5 -Certified areas for FSC in the Amazonian Legal for enterprise type, 2005

\begin{tabular}{lccc}
\hline Tipo de empreendimento & $\begin{array}{c}\text { Área } \\
\text { Certificada }\end{array}$ & $\begin{array}{c}\text { \%a Amazônia } \\
\text { Legal }\end{array}$ & $\begin{array}{c}\text { \% das Florestas } \\
\text { Certificadas no Brasil }\end{array}$ \\
\hline Manejo florestal empresarial & 1216,7 & 72,07 & $40 \%$ \\
Manejo florestal comunitário & 31,5 & 1,87 & $1 \%$ \\
Plantações florestais & 440,1 & 26,07 & $14 \%$ \\
\hline Total & 1688,3 & 100,00 & 3 \\
\hline
\end{tabular}

Fonte: FSC, 2006. 


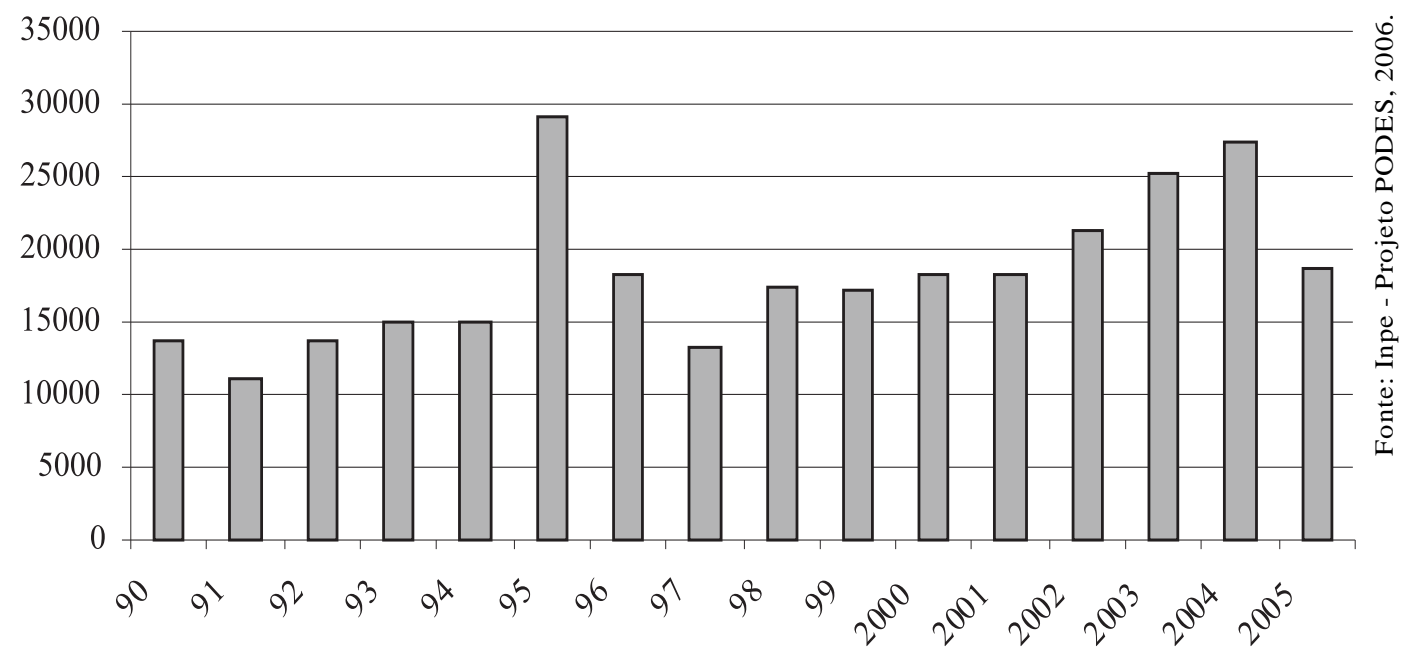

Figura 1 - Área certificada (em ha) por ano no Estado do Pará.

Figure 1 -Certified area (in ha) a year in the Pará-Brazil.

As empresas que tomaram a iniciativa de trabalhar o manejo, seja comunitário, seja empresarial, com empresas certificadoras endossando essas ações, deram um passo significativo para a melhoria do setor florestal no Estado, principalmente se a análise evolui para a constituição de um arranjo produtivo local. Infelizmente, problemas estruturais da Sema e do Ibama do Pará não conseguem viabilizar as autorizações de exploração de madeira de áreas de manejo e nem fazer a fiscalização do comércio de madeira.

\subsection{Constituição de um Arranjo Produtivo no Estado doPará}

O ICn, conforme definido na fórmula 5, foi utilizado para identificar os municípios que possuem alto grau de concentração em determinado setor da economia local. Por isso, o critério para definir os municípios especializados no setor foi adotar um ICn $>3$, conforme Suzigan et al. (2001) e Crocco et al. (2003). Esse valor se justifica no Estado, especificamente para o setor analisado, pelo fato de ser intensivo no emprego de mão-de-obra.

O setor florestal é composto das atividades de extração madeireira e de silvicultura e o setor de madeira e mobiliário, que abrange serrarias, indústrias de laminado e compensado, artefatos e móveis de madeira.

Nos últimos anos, tem-se percebido a evolução do setor de madeira e mobiliário pelo crescimento do ICn, ao contrário do setor floresta. Esse é um forte indício de que a competição nesse setor está aumentando, assim como denota sua importância para a economia do Estado, como pode ser visto na Tabela 6 .

Tabela 6 - Valor médio dos ICn no período de 1998-2003

Table 6-Medium value of Concentration Normalized Index (CNI) for the period of 1998-2003

\begin{tabular}{|c|c|c|c|c|c|c|}
\hline Período & 1998 & 1999 & 2000 & 2001 & 2002 & 2003 \\
\hline & \multicolumn{6}{|c|}{ Madeira/Mobiliário } \\
\hline Média do ICn & 0,6096 & 0,6995 & 1,1733 & 1,1619 & 2,7024 & 3,5679 \\
\hline $\mathrm{N}^{\circ}$ de municípios com $\mathrm{ICn}>$ Média & 32 & 36 & 34 & 31 & 26 & 25 \\
\hline \multirow[t]{2}{*}{ 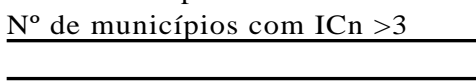 } & 11 & 14 & 25 & 20 & 25 & 25 \\
\hline & \multicolumn{6}{|c|}{ Setor Florestal } \\
\hline Média do ICn & 0,5630 & 0,5423 & 0,7108 & 0,4280 & 0,5684 & 0,3743 \\
\hline $\mathrm{N}^{\circ}$ de municípios com ICn> Média & 15 & 9 & 13 & 20 & 18 & 14 \\
\hline $\mathrm{N}^{\circ}$ de municípios com $\mathrm{ICn}>3$ & 5 & 4 & 6 & 4 & 7 & 5 \\
\hline
\end{tabular}

Fonte: Elaboração dos autores.

R. Árvore, Viçosa-MG, v.33, n.3, p.533-543, 2009 
A Tabela 6 mostra que o número de municípios com ICn acima da média declinou ao longo dos anos. Um fator que pode explicar essa queda é o forte impacto da fiscalização do Ibama, diante das pressões do Ministério do Meio Ambiente e de ONGs ambientalistas, em função da obrigatoriedade da implantação de planos de manejo por parte das empresas para que possam extrair e comercializar legalmente a madeira. A ação do Ibama tornou-se mais eficiente na fiscalização depois que passou a utilizar tecnologias de informações, combinadas com o sensoriamento remoto, imagens de satélites, localização georreferenciada e sensores aerotransportados das áreas de maior exploração florestal. Além disso, está cada vez mais difícil a venda de madeira clandestina, pois o selo verde (que é, na verdade, um carimbo da certificação) tornouse realidade como mecanismo que indica a procedência da madeira e atende a exigências dos países importadores de produtos florestais madeireiros. Isso favoreceu as empresas idôneas e dificultou a ação de empresas informais e, ou, as que operam de forma ilegal.

Com essas iniciativas implantadas, justificamse os dados da Tabela 6 , na qual se observa grande número de municípios concentrados nas atividades floresta e de madeira e mobiliário. Esse número de municípios indica forte concentração de empresas atuando no Estado, em função da abundância de madeira da floresta amazônica.
Com o passar dos anos, tem-se percebido uma queda gradual no número desses municípios e, junto com ela, notado um aumento no ICn do setor madeira e mobiliário, evidenciando que só continuaram a participar dessa atividade empresas com maior poder competitivo, em função da escala e da tecnologia utilizada na extração de madeira, reflorestamento e beneficiamento do produto. Essa queda na concentração de municípios coincide também com o período em que o Ibama passou a praticar medidas fiscalizadoras mais rigorosas no Estado, como pode ser observado em Brito e Barreto (2006), limitando a ação de empresas irregulares, ou seja, há aumento no número de empresas formais no Estado.

Na Tabela 7, pode-se observar que, ao longo dos anos, o número de empresas formais no setor florestal no Pará tem aumentado, principalmente para as atividades de silvicultura e exploração florestal.

A Figura 2 mostra que nos municípios localizados na mesorregião Sudeste Paraense (indicados pelo círculo) se concentram as empresas constituintes do APL, estando localizadas na região pertencente ao arco do desmatamento no Estado do Pará. Esse aspecto evidencia que na direção desse arco também está caminhando uma linha de desenvolvimento do setor florestal e de madeira e mobiliário, pela especialização desses setores na dinâmica de emprego formal na região.

Tabela 7 - Número de empresas formais no setor florestal no Pará com ICn $>3$ Table 7 - Number of formal company in Pará Forest sector with CNI >3

\begin{tabular}{|c|c|c|c|c|c|c|c|c|}
\hline \multirow[b]{2}{*}{$\overline{\text { Atividade }}$} & \multicolumn{7}{|c|}{ Setor Florestal } & \multirow[b]{2}{*}{ TG } \\
\hline & 1998 & 1999 & 2000 & 2001 & 2002 & 2003 & 2004 & \\
\hline Silvicultura, exploração florestal. & 12 & 10 & 14 & 14 & 30 & 39 & 32 & $25,80 *$ \\
\hline Fabricação de produtos de madeira & 33 & 36 & 42 & 38 & 39 & 46 & 45 & $4,93 * *$ \\
\hline Papel de celulose & 3 & 1 & 1 & 2 & 1 & 0 & 0 & $11,10^{\mathrm{ns}}$ \\
\hline Industria de móveis & 1 & 1 & 2 & 2 & 2 & 2 & 1 & $5,07^{\mathrm{ns}}$ \\
\hline \multirow[t]{2}{*}{ Total } & 49 & 48 & 59 & 56 & 72 & 87 & 78 & $10,45 *$ \\
\hline & \multicolumn{8}{|c|}{ Setor Madeira e Mobiliário } \\
\hline Silvicultura, exploração florestal. & 14 & 13 & 21 & 29 & 58 & 87 & 131 & $50,93 *$ \\
\hline Fabricação de produtos de madeira & 390 & 459 & 514 & 538 & 577 & 612 & 625 & $7,81 *$ \\
\hline Papel de celulose & 0 & 0 & 0 & 0 & 0 & 1 & 0 & - \\
\hline Industria de móveis & 5 & 5 & 10 & 7 & 10 & 13 & 7 & $10,99 \mathrm{~ns}$ \\
\hline Total & 409 & 477 & 545 & 574 & 645 & 713 & 763 & $10,69 *$ \\
\hline Total para os Setores & 458 & 525 & 604 & 630 & 717 & 800 & 841 & $10,66^{*}$ \\
\hline
\end{tabular}

Fonte: Elaborado pelo autor a partir da Rais - MTE. * Significativo a 1\%; ** Significativo a 5\%; e ns, não significativo.

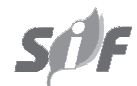

R. Árvore, Viçosa-MG, v.33, n.3, p.533-543, 2009 

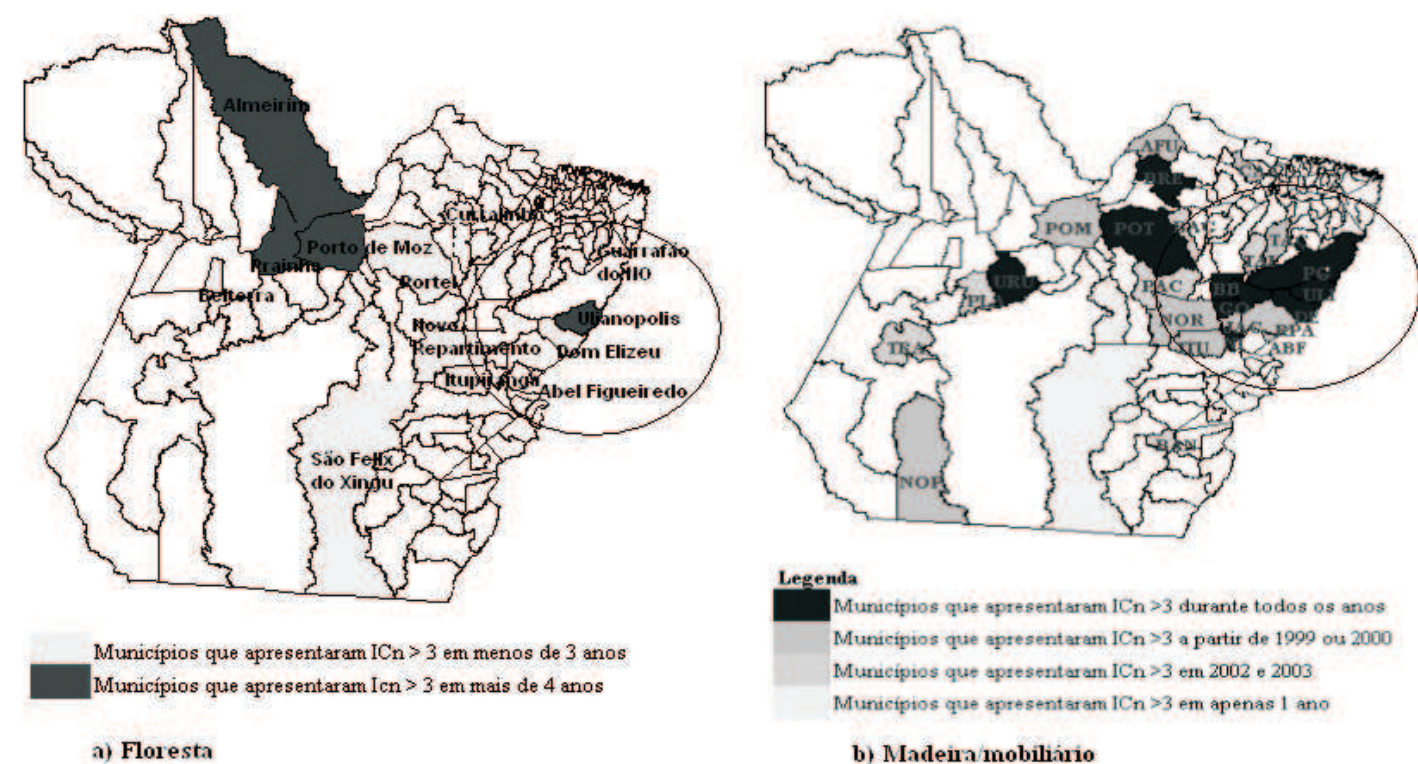

b) Madeira mobiliánio

Figura 3 - Concentração dos setores floresta e madeira/mobiliário no Estado do Pará para o ICN $>3$.

Figure 3 -Concentration of the sections forest, wood and furniture in the Pará-Brazil for CNI>3.

\section{CONCLUSÃO}

As exportações de madeira do Estado do Pará evoluíram, no período de 1998 a 2004, a uma taxa acima de $14 \%$ ao ano, com destaque para os produtos de maior valor agregado, como madeira perfilada, painéis e obras de madeira beneficiada. A participação relativa do superávit da balança comercial do Pará em relação ao Brasil manteve-se em torno dos $19 \%$ entre 2001 e 2005. O número de municípios identificados pelo ICn como de maior concentração de empresas formais ou municípios especializados nas atividades de madeira e mobiliário estabilizou-se em 25; e no setor de exploração florestal e silvicultura, em 5. Isso se deve à exigência do mercado por produtos oriundos de áreas de manejo sustentável, ao aumento da eficiência na fiscalização do Ibama e da Sema-PA e às ações do Ministério do Trabalho com relação ao combate ao trabalho escravo e a outras situações de irregularidades.

\section{REFERÊECIAS}

ABIMCI. Estudos Setoriais 2003 Produtos de Madeira Sólida. Curitiba: 2003.

ALENCAR, A. et al. Desmatamento na Amazônia: indo além da emergência crônica. Manaus: Instituto de Pesquisa Ambiental da Amazônia, 2004. 89p.

R. Árvore, Viçosa-MG, v.33, n.3, p.533-543, 2009
BRITO, B.; BARRETO, P. A eficácia da aplicação da lei de crimes ambientais pelo Ibama para proteção de florestas no Pará. Revista de Direito Ambiental, n.43, p.35-65, 2006.

CROCCO, M. A. et al. Metodologia de identificação de arranjos produtivos locais potenciais. Belo Horizonte: UFMG/ Cedeplar, 2003. (Texto para discussão, 212).

DILLON, W. R.; GOLDSTEIN, M. Multivariate analysis: methods and applications. New York: John Wiley \& Sons, 1984.

FEARnside, P. M. A floresta Amazônia nas mudanças globais. Manaus: Instituto Nacional de Pesquisas da Amazônia, 2003. 134p.

HANSMANN, R.; KOELLNER, T.; SCHOLZ, R. W. Influence of consumers' socioecological and economic orientations on preferences for wood products with sustainability labels. Forest Policy and Economics, v.8, n.3, p.239-250, 2006.

HOMMA, A. K. O. Extrativismo vegetal na Amazônia: limites e oportunidades. Brasília: Embrapa, 1993.

INSTITUTO NACIONAL DE PESQUISAS ESPACIAS - INPE. Monitoramento da floresta. São José dos Campos: 2004. 
KIKER, C. F.; PUTZ, F. E. Ecological certification of forest products: economic challenges. Ecological Economics, v.20, n.1, p.37-51, 1997.

LASTRES, H. M. M et al. Globalização e inovação localizada: experiências e sistemas locais no ambito do Mercosul e proposições de políticas de C\&T. Rio de Janeiro: REDESIST, 1998. (Nota Técnica, 1).

LASTRES, H. M. M.; CASSIOLATO, J. E. Glossário de arranjos e sistemas produtivos e inovativos locais. In: Projeto de Pesquisa: arranjos produtivos locais; uma nova estratégia de ação para o SEBRAE. Rio de Janeiro: REDESIST, 2005.

\section{LENTINI, M. Fatos florestais da} Amazônia. Belém: Imazon, 2005.

MYTELKA, L. K.; FARINELLI, F. Local clusters, innovation systems and sustained competitiveness. In: SEMINÁRIO LOCAL CLUSTERS, INNOVATION SYSTEMS AND SUSTAINED COMPETITIVENESS, IE-BNDES. Rio de Janeiro: 2000.

NOCE, R. et al. Concentrações das exportações no mercado de madeira serrada. Revista Arvore, v.29, n.3, p.431-437, 2005.

OLIVEIRA, A. D.; RIBEIRO, I. S. A.; SCOLFORO, J. R. Análise do mercado internacional de compensado. Revista Árvore, v.29, n.2, p.311-320, 2005.
SANTANA, A. C. Análise da competitividade sistêmica da indústria de madeira no Estado do Pará. Revista de Economia e Agronegócio, v.1, n.2, p.205-230, 2003.

SANTANA, A. C. Arranjos produtivos locais na Amazônia: metodologia para identificação e mapeamento. Belém: ADA, 2004.

SANTANA, A. C.; SANTANA, Á. L. Mapeamento e análise de arranjos produtivos locais na Amazônia. Teoria e Evidência

Econômica, v.12, n.1, p.9-34, 2004.

SAntanA, A. C.; SIlvA, M. C. A. Análise do mercado de ações para políticas: café. Belém: SAGRI-FCAP, 1998.

SANTANA, A. C. A competitividade sistêmica das empresas de madeira da Região Norte. Belém: M \& S, 2002.

SANTANA, A. C. A indústria de madeira do Estado do Pará: análise de competitividade. Novos Cadernos Naea, v.4, p.83-114, 2001.

SANTOS, R. B. N. Análise intersetorial e espacial dos setores extrativo florestal e madeira/mobiliário na economia paraense. 2006. 543f. Dissertação (Mestrado em Ciências Florestais) - Universidade Federal Rural da Amazônia, Belém, 2006.

SUZIGAN, W. et al. Aglomerações industriais no Estado de São Paulo. Economia Aplicada, v.5, n.4, p.698-717, 2001. 
